\title{
How Jordanian Students Learn about Americans? A Case Study at Yarmouk University in Irbid, Jordan
}

\author{
Irene Gibson \& Mohammed S. Banihani* \\ Macalester College, USA Yarmouk University, Jordan \\ Received: $12 / 11 / 2016$ \\ Accepted: 12/2/2017
}

\begin{abstract}
This study investigated how educational programs affect Jordanian students' perceptions of Americans. Students were from Yarmouk University in Jordan. The focus was twofold: first, to document opinions about Americans and American-related topics. Second, to determine if various educational programs relating to Americans impact opinions about Americans. The focus of the study compared students involved in cultural exchange programs to students not involved in exchange programs. This study was based on a questionnaire distributed to a purposeful sample of undergraduate and graduate students at Yarmouk University. Participation in a cultural exchange program was found to not have a significant effect on opinion of Americans. Program participants reported a greater proportion of "very positive" opinions of Americans, and did not hold "very negative" opinions of Americans, but these differences were not statistically significant. When comparing average opinions on Americans and related questions, exchange participants reported on average more positive opinions in cultural categories, but more negative opinions in governmental categories. The average confidence in knowledge about Americans was higher in exchange participants than the confidence of non-participants. Having a more positive opinion of the U.S., American ideas about democracy, American music, movies, and television, and desire to travel to the U.S. all were significantly associated with a more positive opinion about Americans.
\end{abstract}

Keywords: Educational programs, teacher education, personal epistemology, Jordan, USA.

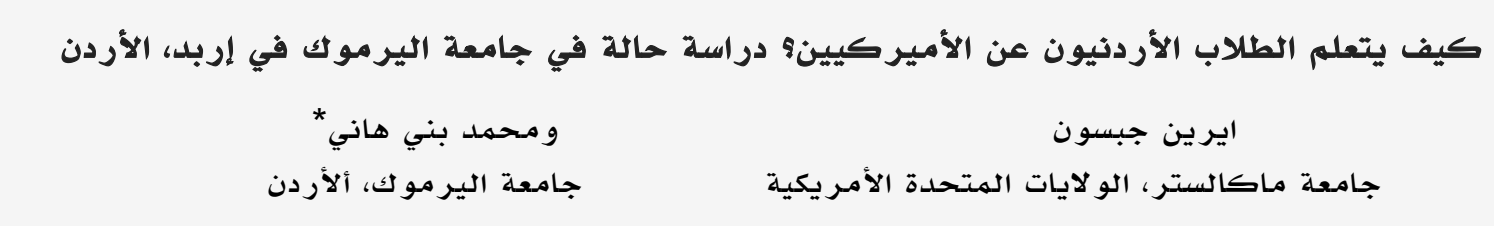

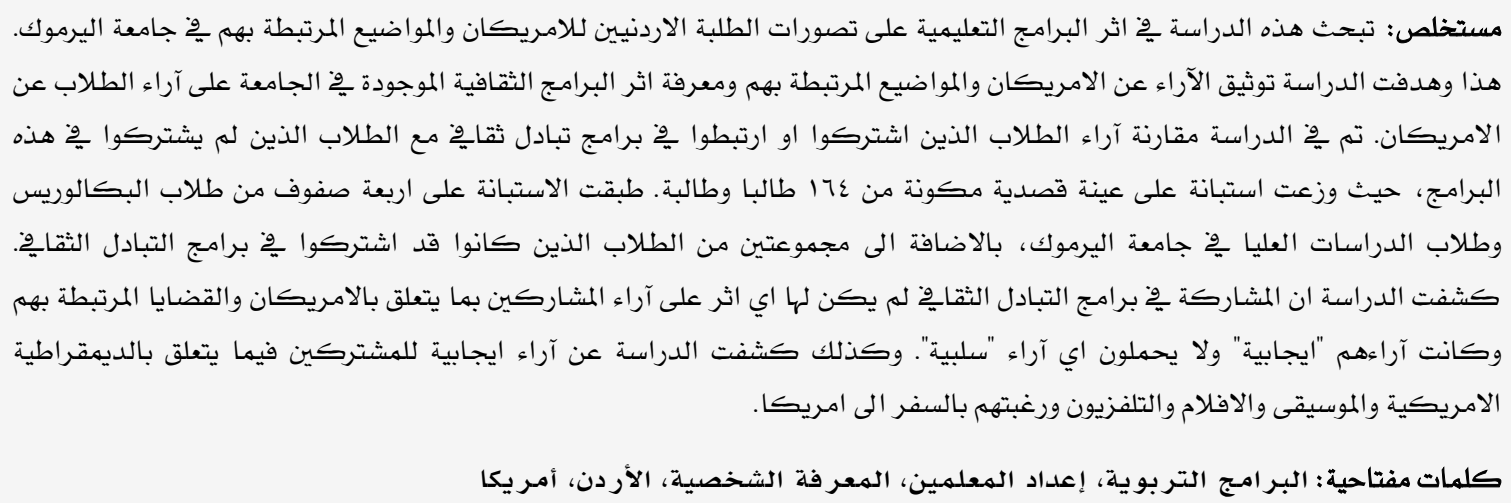

*mbanihani@aou.edu.om 
Although America and the American culture is not a component of Jordan's educational system, it is implicitly integrated into how Jordanian students learn. English is the only foreign language taught in public schools and in most private schools, and language classes begin at the elementary level and continue until university. Both public and private universities use English in teaching sciences and business. Jordanian universities also give students exposure to American studies and American culture, though this varies depending upon major and professor. Outside academics, students often overhear or take part in discussions about regional politics involving U.S. policy. Jordanians are also exposed to a wide variety of American media in daily life through internet, music, movies, and television.

But what is the impact of this exposure on Jordanian perceptions of Americans? Learning a foreign language and understanding a foreign culture are not synonymous, and American media often reinforces stereotypes about the United States. In addition, U.S. foreign policy does not necessarily represent attitudes of the U.S. public. Ideally, educational programs such as classes or cultural exchanges would best represent the American people, as the purpose of these programs is to increase students' understanding of Americans. Yet it is difficult to determine how exposure to these programs effect Jordanian students' perception; no studies these authors found pursued this information. It is important that American cultural classes and related programs within Jordan's education system both accurately represent Americans and do so in a manner that best enables Jordanian students to learn and understand. This is critical not only as a measurement of success for these programs, but also as a life skill for Jordanian students to learn cross-cultural communication.

The purpose of this study was to evaluate how educational programs affect Jordanian students' perceptions of Americans through the case study of Yarmouk University in Irbid, Jordan. The focus was twofold: to document opinions about Americans and Americanrelated topics, and to determine if various educational programs relating to Americans and opinions about American-related topics impact opinions about Americans themselves. The study compares students involved in cul- tural exchange programs to students not involved. However, common external methods of learning about Americans which shape the perception of these students were also investigated. These secondary means of learning will be compared to primary exposure to see to what extent various methods of learning impact Jordanian student perceptions.

Surveys were distributed to a purposefully selected student sample including both undergraduate and graduate students. In addition to responding to the survey questions, students were asked to add a written explanation for each of their responses. Surveys were conducted in July 2014.

Yarmouk University was chosen as a case study because it was best suited to the needs of the study. One of the authors (Gibson) studied a semester of Arabic through a cultural exchange program at Yarmouk University, and the co-author (Banihani) is a professor at Yarmouk University. In addition, Yarmouk is suited to the study as it is a prestigious university located outside the capital. Yarmouk is considered the second best university in Jordan. Its location in Irbid, Jordan, places it apart from the common tourist exposure in Amman, decreasing any confounding effect of exposures to tourist interactions.

According to Yarmouk University's own statistics, the university has a 35,000 student body, about 3,500 of which are non-Jordanian. Though these international students come from about 40 different countries, the majority are Malaysian or from nearby Arab states. The largest groups of international students are as follows: Malaysian (800), Saudi Arabian (400), Syrian (350), Bahraini (170), and Yemeni (160). In addition, throughout the year various American exchange programs bring students to Yarmouk, primarily for Arabic language programs, though these students are not officially enrolled.

This paper contains three sections: a literature review, study results, and a conclusion. The first section's literature review briefly explains general theory on cross-cultural perceptions, as well as providing background on preexisting surveys and academia regarding Jordanian perceptions of Americans. The second section shows and explains the survey results. The final section highlights the important findings of the results and their significance, and 
suggests further expansions on this study for the future.

\section{Literature Review}

\section{General Theory on Cross-Cultural Perception}

A large body of studies is concerned with how different cultures perceive each other. First and foremost, it must be recognized that different cultures have different attitudes and methods of perception (Kitayama, Duffy, Kawamura, and Larsen, 2003). This can create even fundamental differences in action, such as determining how a person tends to perform a given task. However, this response is not correlated to genetics, (as Hernstein and Murray's claim in "The Bell Curve") (Herrnstein and Charles, 1994), but rather one's surroundings. For example, a person of one culture, when exposed to the environment of a different culture, alters his/her tendency to perform a task to fit with the different culture.

The significance of this finding explains that, though initially cultures may exhibit small differences that seem foreign, people naturally adapt to their surroundings. In theoretical example, if Jordanians and Americans perform a task differently, when Americans visit Jordan, they began to perform the task in a more Jordanian manner, and vice versa. Though initially minute details of a person's action may not fit with the culture or seem odd, eventually he/she will adapt to the new characteristics of a culture. The Bennett scale illustrates this in a continuum of adaptation in cultural relativism. It proposes five stages of adaptations that a sojourner will experience. Starting with denial of differences, these stages end with integration, in which a person can move between various worldviews (Bennett in Paige, 1993). Based on this scale, one can assume Jordanian perceptions of Americans will be different depending upon the extent to which Americans have adapted to the new cultural nuances of their surroundings, and the extent to which Jordanians are able to accept that different American cultural nuances. The stage at which each Jordanian is at will affect his or her interpretation of both Americans in person and from secondary exposure, such as films. Culture is a determining factor both in social perception and the physiological response determining this perception (Freeman, Nicholas, and Ambady, 2009). In other words, how different cultures perceive is different: "In sum, one's cultural background determines the en- gagement of a frontparietal attentional network when making basic perceptual judgments" (Kitayama, Duffy, Kawamura, and Larsen, 2003, p. 195). This causes cultural differences in one's ability to recognize emotions, making a person more capable of accurately recognizing emotions in his or her own culture (Elfenbein and Ambady, 2014, p.163).

Body language also carries different impact; though cultures uniformly assign certain movements certain meaning (i.e. nose wrinkling as disgust) the impression of that sign may have different significance. For example, a woman in America speaking quietly to the cashier and avoiding his eyes means that she is demure and shy, traits not valued in American culture, and so she is likely viewed in a negative light as annoying and difficult. The same soft-spoken woman in Jordan is also seen as demure and shy, but these traits are highly valued in women in Jordanian culture, and so she is likely viewed in a positive light as modest and good. However, just as different settings alter a person's manner in which they perform a task, so too can a person learn to identify cultural emotions from other cultures; recognizing emotions is a learned, not inherent, trait (Elfenbein and Ambady, 2014).

Again, this has implications in our study because it signals both Jordanians and Americans may not be able to easily understand one another's emotions. Additionally, they will likely put value on different traits, adding small confusion to action and communication. These potential misunderstandings effect how Jordanians interpret American actions, and vice versa.

The interpretation of language also differs between cultures, even if the same language is being spoken. According to a study of crosscultural communication: "In many cases, different cultural expectations and practices can affect the way in which individuals from different cultures both present and interpret spoken or written information" (Ulijn and Amant, 2000, p. 220). Therefore, not only physical American movements, but also written information about Americans, may be perceived differently between Jordanians and Americans. ${ }^{1}$

\footnotetext{
${ }^{1}$ Our survey addressed this issue by being mutually created by both an American and a Jordanian who were familiar with both Arabic and English.
} 
Perception of another also relates directly to the group that person represents. It has been found that if a person is seen as a larger threat, racism towards that person increases (FalomirPichastor, Manuel, Muñoz-Rojas, Invernizzi, and Mugny, 2004). This relates to Jordanians because in Jordan, the U.S. is seen as a large threat to regional stability. According to a Brookings study in 2010, the U.S. is viewed as the second greatest threat by Middle Eastern countries (second to Israel) (Telhami, 2010).

Similarly, an American in Jordan may see Middle Easterners as a threat due to recent violence in the region. This may cause both parties to be racist against each other or act uncharacteristically in interaction. This is particularly important to consider because seeing a group as a threat may not be consciously recognized; implicit negative feelings towards groups have been shown without the person knowing they disliked a certain group (Freeman, Nicholas, and Ambady, 2009). If Jordanians or Americans do not know they are racist towards the other, then they may judge their perceptions to be unbiased when they in fact are.

The general theory behind cross-cultural perception shows that different cultures not only perceive in different ways, but attach different significance to the same action and perform the same task in different manners. Emotion, speech, and writings are interpreted differently. The more different the culture, the more pronounced this difference in interpretation. In addition, the group one is associated with has a heavy impact on how that person is perceived. Yet these differences are not necessarily genetic; one can learn how to better interpret a different culture. This potential lends support to the idea that accurate learning about Americans should enable Jordanians to perceive American culture more accurately and potentially use this perception in an operational capacity. However, as studying other culture may expose different possibilities, differences may also give rise to rejection of the other culture.

\section{Current Academia on Jordanian Perceptions of Americans}

Most data concerning Jordanian perceptions of Americans is collected in various opinion polls and surveys designed for Middle Eastern countries. Though none of these are Jordan specific, and therefore do not have substantial depth, selections from these studies provide groundwork and comparisons for our own findings. One of the best sources of data is the Pew Research Center's (2002-2013a, b, c) Global Attitudes Project. Pew has been gracious enough to allow us to model from several questions in its research for our own survey, giving us a baseline for comparison purposes. These questions are: Do you have a favorable or unfavorable view of the American people? Do you have a favorable or unfavorable view of the U.S.? Is it good or bad that American ideas and customs are spreading here? Do you like or dislike American ideas about democracy? Do you like or dislike American music, movies and television? Table 1 and Figure 1 below summarize the Pew respondents' views of the American people since 2002, and highlights the purpose of our own study (Pew Research Centre, 2002-2013b).

Table 1

"Do you have a favorable or unfavorable view of the american people?"

\begin{tabular}{ccc}
\multicolumn{3}{c}{ of the american people?" } \\
\hline year & Favorable (\%) & Unfavorable (\%) \\
\hline 2002 & 54 & 46 \\
2003 & 18 & 82 \\
2004 & 21 & 73 \\
2005 & 34 & 66 \\
2016 & 39 & 61 \\
2007 & 36 & 62 \\
2008 & 36 & 63 \\
2009 & 39 & 60 \\
2010 & 44 & 54 \\
2011 & 37 & 61 \\
2012 & 31 & 67 \\
2013 & 31 & 65
\end{tabular}

Table 1 and Figure 1 show that Jordanians are currently more likely to view Americans negatively than positively, a trend which also holds true in the Pew results for American-related ideas. After the invasion of Iraq in 2003, opinions dropped steeply regarding American people and the state, but increased in positivity towards American democracy and media representations. However, opinions have become more positive since then. 


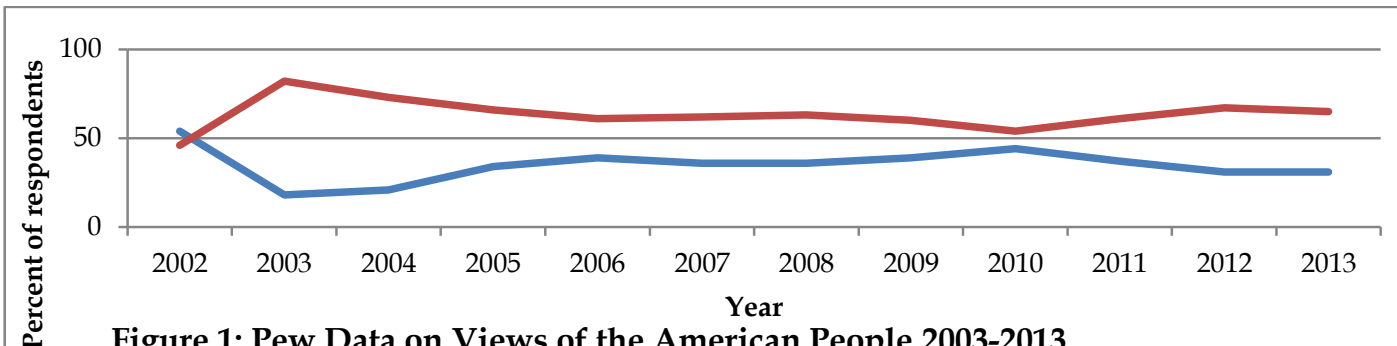

Figure 1: Pew Data on Views of the American People 2003-2013

Favorable (\%) Unfavorable (\%)

It seems that the most influential factor in fostering negative opinion on Americans has been U.S. foreign policy. This finding has been repeated consistently throughout various studies. Specific points of contention with U.S. policy include the Iraq War, War on Terrorism, Israel alliance, and U.S. intervention without considering regional effects (Kohut, 2005; Telhami, 2010). In 2002 and 2003, after the invasion of Afghanistan and Iraq, the U.S. was less popular in the Middle East than anywhere else in the world (Kohut, 2005). The issue of Israel's alliance with the U.S. is also a hot point of contention throughout the Middle East and mars the U.S. and American image in the eyes of Jordanians, particularly as over half of their population is of Palestinian origin (Telhami, 2010).

Has what Jordanians view as American is political mistakes recently established increased negativity towards Americans? A June 2014 poll found that $18 \%$ of Jordanians had favorable views of the U.S., and 75\% had unfavorable views (Zogby Research Services, 2014). Based on the Pew 2013 data listed in Table 1, this is a $10 \%$ increase in unfavorable views towards the U.S. If politically related, this could be a sign of raised discontent with the rise of ISIS in Iraq. This turn of negativity in opinion could show that Jordanians blame Iraq's spillover violence on the U.S. for not establishing stability.

The relation of U.S. policy to American opinion is especially critical to consider for the time period of this study. During the summer of 2014, tensions between Israelis and Palestinians were especially high because of the ongoing war. As a result, many Jordanian sentiments were likely affected by the media surrounding the war between Gaza and Israel, which therefore may have affected their survey responses, as America and Israel are known to be allies. The surveyors recognize this study was conducted at a time when tensions were uncharacteristically high. In order to anticipate this potential effect, Yarmouk professors were asked about what they thought the effect the ongoing politics would have on the survey. Each professor replied similarly: through a few students would allow the current politics to affect their opinion on Americans, the large majority of student opinions on Americans would not be affected.

Yet outside politics, there are several additional theories as to why Jordanians may perceive Americans negatively. Perhaps the most famous theory supporting the idea of negative perceptions is the Clash of Civilizations theory which portrays Islam and the West as natural enemies (Tessler and Robbins, 2007). However, there was a large backlash against this theory, and Said called it a "gimmick" and staunchly decry the idea (Said, 2001).

In addition to such theories, there are several studies which concentrate on why people express anti-American sentiments. Multiple traits have been shown, hypothesized, and argued to be correlated to anti-Americanism, among them economic situation, religiousness, and government mistrust, but the extent to which each may or may not be related is still debated.

It is also important to conside the reality that stereotypes about Americans in the Middle Eastern world are often rampant and negative (PBS, 2002). Westerners are portrayed as rich, hypocritical, having few values, and promiscuous. Again, this may be a response to the large threat level the U.S. has in the Middle East; but it may also be that stereotypes abound in popular media. To clarify, it is often the American media itself that perpetuates these stereotypes, not Middle Eastern media. For example, shows on MTV are well-known, and though they come from American culture, they also project and reinforce multiple 
stereotypes about American culture. The championing of exorbitant lifestyles and idolized celebrities in America are rampant, and anyone with the internet can access this phenomenon. Though the access to internet in the study population is unknown, the street running alongside Yarmouk University purportedly has more internet cafes than any other street in the world, and social media has increased hugely in popularity within the Arab world. Therefore, it is estimated that the majority of Jordanians interviewed do have access to internet resources.

Current academia on Jordanian perceptions of Americans and related associations shows that these perceptions are generally negative, though Pew data shows they may be importing with time. Jordanian opinions are heavily based on U.S. foreign policy in the region, though also have exposure to stereotypes in novels and media. Almost no studies have been done on Jordanian exposure to actual Americans and how this may affect impressions. The Arab American Institute, however, did conduct a study on Jordanian exposure to Americans, but it was done in 2004 and was rather small (AAI, 2004). And again, no studies these authors found considered how Jordanians learned about Americans as a factor affecting opinion. Overall, there is much hypothesized but little known about how Jordanian impressions are influenced outside of U.S. foreign policy.

\section{Method}

This study is based on a survey distributed at Yarmouk University. Specifically, it was distributed to a purposeful sample of undergraduate and graduate classes based on personal contact with some instructors. The survey was given to six different classes, four of them in the Education Department and two in the Language Center where American students attend Arabic language programs. Gibson was a previous participant in one of these programs. In total, 164 questionnaires were distributed, of which 153 student responses were collected. Eleven questionnaires were discarded due to students reporting that they were non-Jordanians. Of these, 38 students had been or were involved in cross-cultural exchange programs with Americans from either the University of Virginia Arabic Program or the CET Intensive Arabic Language Program at Yarmouk. The cross cultural programs only involve Americans in Jordan but do not involve Jordanians who have been in the U.S. In both of these programs, survey responders either acted as language partners, roommates, or worked in some other capacity with the American students visiting Yarmouk University. Additional students counted within the cross-cultural exchange group were from the greater population surveyed who responded "yes" to the question, "Have you participated in an exchange program with Americans?" Undergraduate students were surveyed from a "Principles of Education" class, or a "Civic of Education" class, both university requirements. Masters students were surveyed from an Education MA requirement and English instructions class. Classes were selected from within the Education Department because graduate students in this department come from a wide variety of majors and therefore contribute different backgrounds to the study.

Students were given approximately fifteen minutes in class to fill out the survey, which involved both multiple choice and free response questions. Questions concerned basic demographic information, means of learning about Americans, exposure to Americans, and opinions on Americans and topics related to Americans. To determine opinions on Americans, survey participants were given questions with five options (see Table 2) in ascending order from "very negative" to "very positive", with "no opinion" in the middle.

\section{Results}

Table 2 describes characteristics of the participants, overall and by exchange participation status. Numbers reported as percentages are actual percentages within the category. As not all respondents answered all questions, not all percentages totals add up to 100 .

Chi-squared tests were used to compare the study groups. Total percentages are reported for each variable, as well as the extent of its significance. Factors found to be significant were included in a multivariate linear regression model, with the dependent variable being opinion of Americans. A post-hoc power calculation was performed on the variables in the regression. The mean opinion about Americans, as well as its significance, is also presented. Table 2 shows the demographic information of participants and source of learning about Americans. 
Table 2

Survey Population Demographics, Confidence, and Source of Learning about Americans (\%)

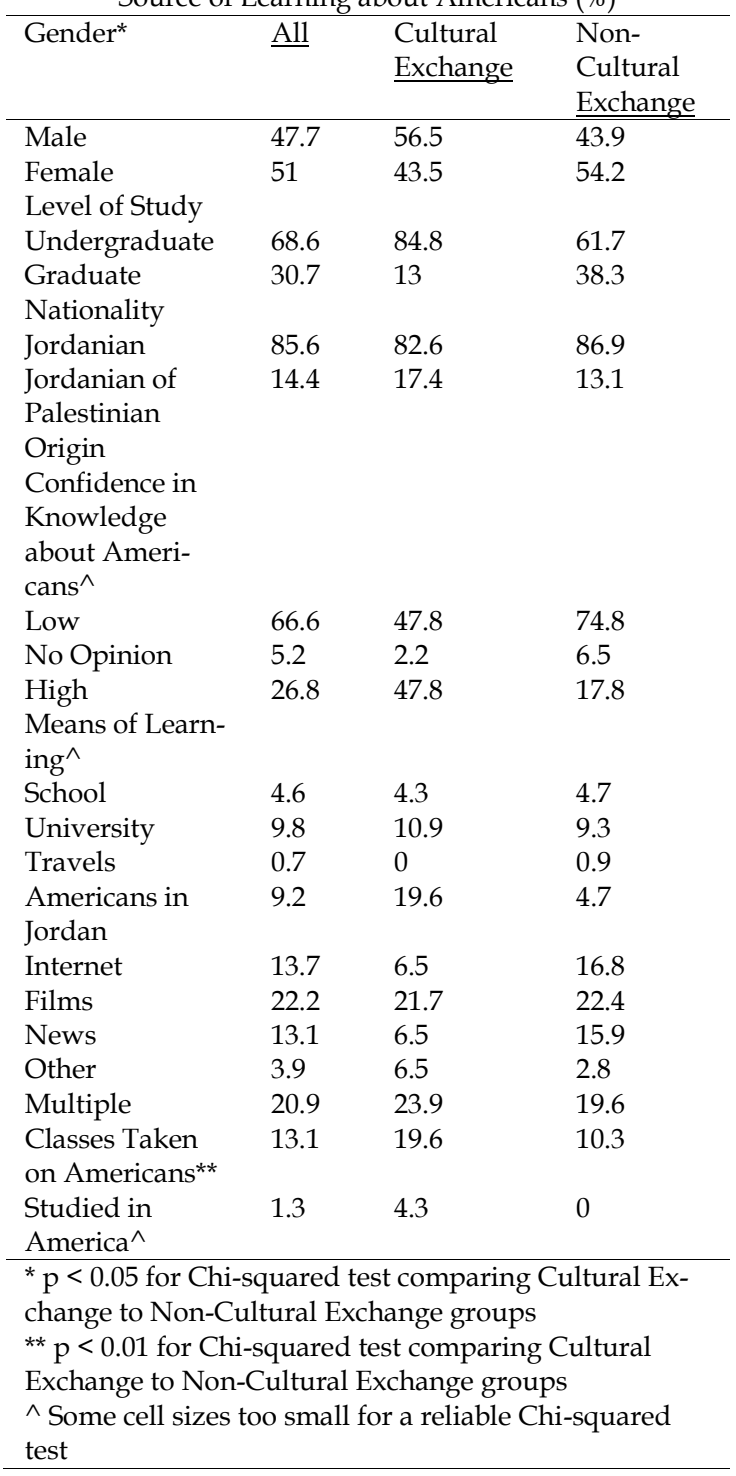

The only statistically significant differences between the group characteristics were in "Gender" and "Classes Taken on Americans." The cultural exchange group contained about 13 percentage points more males, and was about twice as likely to take classes on Americans ( 2 out of 10 versus 1 out of 10). However, neither of these variables was significantly associated with opinion of Americans in the multivariate regression ${ }^{2}$ and therefore were deemed to not largely affect the overall outcome on this opinion.

Though both males and females had about equal representation in the total study, there were about 13 percentage points more males

2 This regression included the other factors that were statistically significantly associated with opinion of Americans. than females in the exchange group. Undergraduate students made up the majorities of all groups, and held a large majority of crosscultural exchange students (above 80\%). All groups were largely composed of Jordanian students. A significant difference between groups was in how confident students were in their knowledge about Americans; a higher portion of exchange students (48\%) reported high confidence than did non-exchange students $(18 \%)$. Means of learning shared relatively similar percentage distribution, though exchange participants reported learning far more from Americans in Jordan, and far less from the internet and news, than nonexchange participants. Cultural exchange students also took more classes on Americans, and were the only students to report having studied in America.

The participation of a student in a cultural exchange program was found to not have a significant effect on opinion of Americans as shown in Table 3. The exchange program participants surveyed reported a greater proportion of "very positive" opinions of Americans, and did not hold "very negative" opinions of Americans, but these differences were not statistically significant. A post-hoc power calculation of the general linear model showed that if the true difference was that cultural exchange students had a $6 \%$ more positive opinion score regarding Americans, a study with this sample size has an observed power of $26 \%$ to find a statistically significant difference in opinion. In other words, this study had about a 1 in 4 chance of finding a relationship between exchange programs and opinion of Americans, if the actual difference was $6 \%$. Table 3 shows the cultural exchange and non-cultural exchange students' opinion of Americans.

\begin{tabular}{lccc}
\multicolumn{4}{c}{ Table 3 } \\
Cultural & $\begin{array}{c}\text { Opinions on Americans (\%) } \\
\text { Non- } \\
\text { Opinion }\end{array}$ & $\begin{array}{c}\text { Exchange } \\
\text { Cultural } \\
\text { All }\end{array}$ & Exchange \\
& 5.9 & 0 & \\
\hline Very Negative & 20.9 & 26.1 & 8.4 \\
Negative & 32.7 & 26.1 & 35.7 \\
No Opinion & 34 & 34.8 & 33.6 \\
Positive & 4.6 & 8.7 & 2.8 \\
Very Positive & \multicolumn{4}{l}{} \\
\hline Differences were not statistically significant in chi- \\
square test
\end{tabular}

Opinion on topics related to Americans all had significant relationships with opinion of Americans as shown in Table 4. As seen in Table 4, each had statistically significant 
results, with $\mathrm{p}<0.01$ or less. In the multivariate regression a more positive opinion of the U.S., American ideas about democracy, American music, movies, and television (hereafter referred to as American media), and desire to travel to the U.S. all were significantly associated with a more positive opinion about Americans. Most notably, opinion of the U.S. and opinion of American media was strongly associated with positive opinion of Americans $(\mathrm{p} \leq 0.001)$.

Exchange students were less likely to report "negative" or "no opinion" regarding American media, having about a $10 \%$ difference in both groups compared to non-exchange students; exchange students had about a $25 \%$ higher total reporting very positive opinions. Desire to travel to America also exhibited a large difference in percentage distributions between groups, where non-exchange students wanted to travel to America more than exchange students, with an about $10 \%$ difference in total.

The five response options (very negative to very positive) are grouped into three groups of "negative", "no opinion", and "positive."

The only statistically significant difference between group means was in the category of "Confidence in Knowledge about Americans," meaning the average confidence in knowledge about Americans was higher in exchange participants than the confidence of nonparticipants Table 5. When comparing average opinions on Americans and related questions, exchange participants reported on average more positive opinions in cultural categories, but more negative opinions in governmental categories. The largest variation between categories was in confidence of knowledge about Americans, where exchange students felt 0.77 points more positively about their knowledge than non-exchange students. Exchange students also felt more positively about American movies, music, and television, American customs and ideas spreading in Jordan, and Americans, at a difference of $0.41,0.26$, and 0.23 , points respectively. However, exchange participants felt more negatively about the U.S. and American ideas about democracy, though these were less than a 0.20 difference.
Table 4

Opinion on Topics Related to Americans (\%)

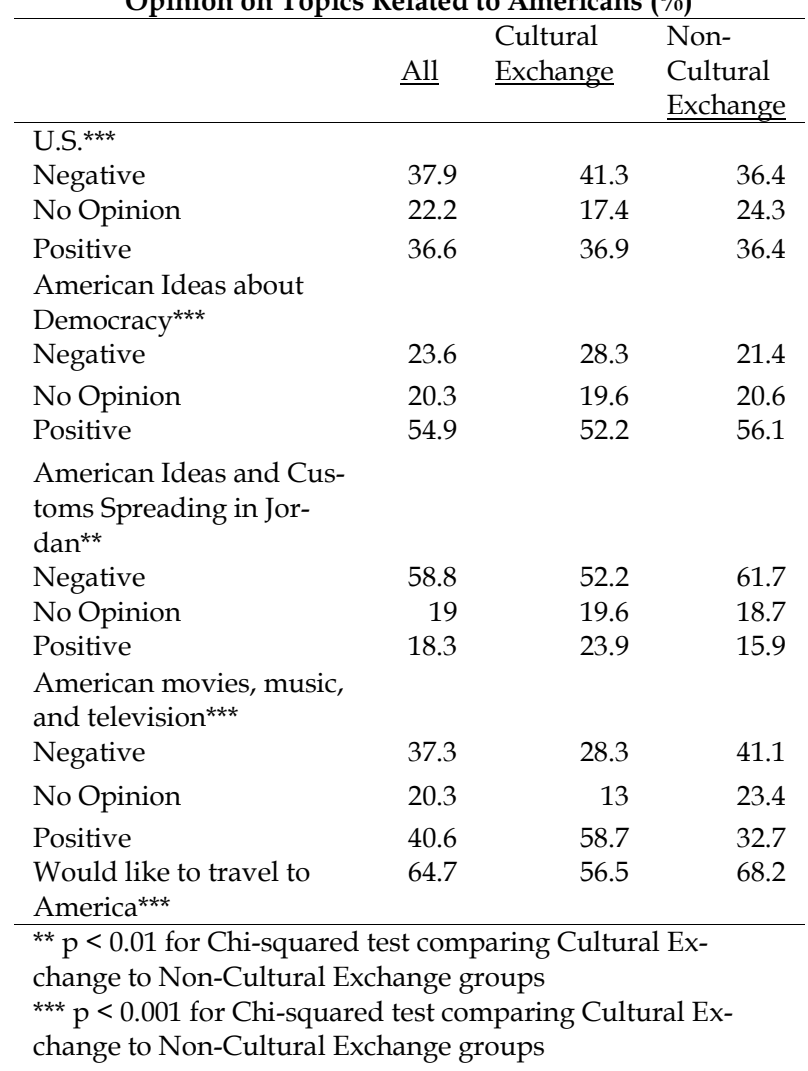

Table 5

Mean Opinion on Topics Related to Americans

\begin{tabular}{llll}
\multicolumn{4}{c}{ Mean Opinion on Topics Related to Americans } \\
\hline $\begin{array}{l}\text { Average opinion score } \\
\text { about... }\end{array}$ & All & $\begin{array}{l}\text { Cultural } \\
\text { Exchange }\end{array}$ & $\begin{array}{l}\text { Non- } \\
\text { Cultural } \\
\text { Exchange }\end{array}$ \\
\hline Americans & 0.11 & 0.27 & 0.04 \\
$\begin{array}{l}\text { U.S. } \\
\text { American ideas about }\end{array}$ & -0.05 & -0.11 & -0.03 \\
$\begin{array}{l}\text { Democracy } \\
\text { American Customs and }\end{array}$ & -0.63 & 0.24 & 0.42 \\
$\begin{array}{l}\text { Ideas Spreading in Jordan } \\
\text { American Movies, Music, } \\
\text { and TV }\end{array}$ & 0.02 & 0.30 & -0.71 \\
$\begin{array}{l}\text { Confidence in Knowledge } \\
\text { about Americans** }\end{array}$ & -0.52 & 0.02 & -0.11 \\
\hline
\end{tabular}

Note. Scale $-\mathbf{2}$ (very negative opinion) to $\mathbf{2}$ (very positive opinion)

${ }^{* * *} \mathrm{p}<0.001$ for a t-test comparing Cultural Exchange to NonCultural Exchange groups, equal variances assumed

In a multivariate linear model that simultaneously adjusted for the factors shown in Table 6, (i.e., the factors found to have chi-squared significance), opinion about Americans was significantly associated with opinions of the U.S., with American ideas about democracy, with American customs and ideas spreading in Jordan, with American movies, music, and TV, and with travel to America. When opinion on each of these variables increased by one point on a five point scale, opinion on Americans increased $0.31,0.13,0.21$, and 0.35 points respectively (also on a five point scale). In other words, each of the four mentioned factors 
had a positive association with what students thought of Americans. Travel to America and opinion about the U.S. were associated with the most positive effect.

Table 6

Post-Hoc Power Calculation of General Linear Model for Significant Variables

\begin{tabular}{|c|c|c|c|c|}
\hline $\begin{array}{l}95 \% \text { Confidence } \\
\text { Variables }\end{array}$ & Beta & Significance & Lower & Upper \\
\hline Gender & 0.10 & 0.44 & -0.16 & 0.37 \\
\hline $\begin{array}{l}\text { Confidence in } \\
\text { Knowledge }\end{array}$ & 0.07 & 0.26 & -0.05 & 0.18 \\
\hline $\begin{array}{l}\text { Taken Classes } \\
\text { on Americans }\end{array}$ & 0.02 & 0.91 & -0.37 & 0.41 \\
\hline $\begin{array}{l}\text { Travel to Amer- } \\
\text { ica* }\end{array}$ & 0.35 & 0.02 & 0.06 & 0.64 \\
\hline $\begin{array}{l}\text { Opinion of... } \\
\text { U.S.*** }\end{array}$ & 0.31 & 0.00 & 0.18 & 0.43 \\
\hline $\begin{array}{l}\text { American Ideas } \\
\text { about Democra- } \\
\text { cy* }^{*}\end{array}$ & 0.13 & 0.03 & 0.01 & 0.25 \\
\hline $\begin{array}{l}\text { American Cus- } \\
\text { toms and Ideas } \\
\text { Spreading in } \\
\text { Jordan }\end{array}$ & 0.08 & 0.18 & -0.04 & 0.21 \\
\hline $\begin{array}{l}\text { American Mov- } \\
\text { ies, Music, and } \\
\text { TV }^{* *}\end{array}$ & 0.21 & 0.00 & 0.09 & 0.32 \\
\hline \multicolumn{5}{|c|}{$\begin{array}{l}\text { Note. Scale }-2 \text { (very negative opinion) to } 2 \text { (very positive } \\
\text { opinion) } \\
{ }^{*} \mathrm{p}<0.05 \text { for Chi-squared test comparing Cultural Exchange } \\
\text { to Non-Cultural Exchange groups } \\
{ }^{* *} \mathrm{p}<0.01 \text { for Chi-squared test comparing Cultural Ex- } \\
\text { change to Non-Cultural Exchange groups } \\
{ }^{* * *} \mathrm{p}<0.001 \text { for Chi-squared test comparing Cultural Ex- } \\
\text { change to Non-Cultural Exchange groups }\end{array}$} \\
\hline
\end{tabular}

\section{Written Responses}

Respondents were asked to justify their answers to each opinion question and the means of learning question, in addition to having space to write additional comments. A random sample 3 of these responses was considered for this analysis. The findings of our study largely confirmed the aforementioned academic literature regarding cross-cultural communication and Jordanian opinion polls.

The differences in culture and cultural interpretations were exemplified through a negative opinion of the U.S. and American customs and ideas spreading in Jordan. Many Jordanians noted that the cultural appropriation of American culture in Jordan was misused, and often only negative aspects that contradicted Jordanian culture were adapted: "unfortunately most customs are transferred blindly and in

\footnotetext{
${ }^{3}$ Including 10 respondents from each class or program; 50 surveys total.
}

the end will be negative," and "I am not against customs and traditions of Americans. But I am against the blind imitation." The "blind imitation" phrase appeared numerous times in survey responses, showing that idea of American customs and ideas spreading appeared to be negative not necessarily because of a negative opinion of these traits, but because they were poorly and incorrectly imitated within Jordanian culture. The commentary on different social perceptions of the same action also clarified this point, "I like people who live their life as they want. Their life is pretty and progressive and people do not intervene in other people's lives... They can exchange conversations with each other. But this is strange and not allowed in our culture, and of course it is wrong." Though American customs and ideas seemed to be valued by respondents, their spreading in Jordan was viewed overall as negative due to the idea that they were incorrectly represented and therefore contrary to the culture.

The racism expected from threatened groups was also prevalent in survey responses, showing both sides of the issue: Jordanian racism against Americans seen as threats, and citing of racist Americans who viewed Jordanians as a threat. Racism was much more prevalent in non-exchange student responses, which may also explain the fact none of them held "very negative" opinions of Americans. Survey responses were also dominated by stereotypes about Americans, such as: "respectful of time, faithful at work, seek knowledge, optimistic." Jordanians also often self-identified with stereotypes, such as "generous, kind, courageous, strong family ties." The grand majority of respondents did not identify any negative traits with Jordanians; though there were some negative stereotypes about Americans, these varied. The prevalence of stereotypes within responses is justified, in American traits, by the overall low confidence in knowledge about Americans that students reported. Some students withheld their opinions with the reasoning that they did not personally know any Americans.

Though many students recognized they did not know much about Americans, many had strong opinions of the U.S. Comments reconfirmed the study finding of that opinion of the U.S. influenced opinion of Americans, and that politics played a large role in opinion of the U.S. Sometimes, students would justify a 
negative opinion of Americans by citing reasons they disliked the U.S. Survey comments mainly focused on the larger pattern of U.S. intervention in Middle Eastern countries in general, sometimes on perceived bias against Arab Muslims. Israel was sometimes mentioned; "I explained earlier that my answer [on opinion of the U.S.] is negative because of the American interference in other countries, especially its destruction of the Arab countries and its support to Israel." Yet the political nature may not be entirely due to the fact that Jordanians seek to integrate politics, but because they are integrated into everyday life. Many Jordanians cited ease of access for their reasons of choosing various means of learning, particularly for news and internet users. Because both of these sites are highly political, this may contribute to the association of U.S. opinion with politics.

Curiously, responses about American democracy were positive overall, though this also played into the perception of politics. Many students offered stereotypical reasons of freedom for their positivity, "Democracy is represented by respect of opinion and the opinion of the other the election of the representatives in the government, and the freedom of speech, all these are guaranteed in America." However, a large portion also commented about how the U.S. limits its democracy to its own citizens: "They apply it to themselves but not to the rest of the world." The de juris idea of democracy was seen in a very positive light, while its de facto application was viewed negatively.

However, opinions on Americans overall, from cultural exchange students, and from non-cultural exchange students, were positive. In-person interactions students had with Americans seemed to largely affect their opinion: "As people, they are great. It is different from what we were expecting from the name 'America' which is scary and threatening, and it is the reason behind destruction in the Arab countries." Exchange students with this exposure also had a higher tendency of distinguishing Americans from the U.S. in their responses than non-exchange students. This may explain the exchange student tendency to have higher opinions in cultural categories than nonexchange students.

Yet in both student groups, films were the most often cited means of learning about
Americans, and had a significant relationship with opinion on Americans. When discussing the reasoning behind learning from films, students expressed general belief that this media accurately represented American life: "they provide knowledge about how Americans live and deal with different situations in their life, and give us a good idea about the natural and practical life of Americans." Ease of availability was also often cited as reasoning behind learning the most from films. As opinion of American media was one of the variables most strongly associated with positive American perception, it seems that most of these students not only learned from media, but formed positive opinions from it.

\section{Conclusion}

\section{Summary and Significance of Results}

The participation of a student in a cultural exchange program was found not to be significantly associated with opinion about Americans. The exchange program participants surveyed reported a greater proportion of "very positive" opinions of Americans, and did not hold "very negative" opinions of Americans, but these differences were not statistically significant. When comparing average opinions about Americans and related questions, exchange participants reported on average more positive opinions in cultural categories ${ }^{4}$, but more negative opinions in governmental categories. ${ }^{5}$ The only statistically significance difference between group means was in the category of "Confidence in Knowledge about Americans," meaning the average confidence in knowledge about Americans was higher in exchange participants than the confidence of non-participants. This may have been due to direct learning, as exchange students were more likely to report this means, when nonexchange students were more likely to report learning from the internet or news. By examining general demographic trends, it seems that exchange participants in the study sample had a greater tendency for direct learning about Americans, such as making contact and taking

\footnotetext{
4 These being opinion of Americans, opinion of American customs and ideas spreading in Jordan, and opinion of American movies, music, and TV

5 These being opinion of U.S. and opinion of American ideas about democracy
} 
classes, than those who did not participate in programs. This relationship with involvement could be a cause, or effect, of students participating in such programs. In other words, students involved in exchanges may already be predisposed to participate in direct learning about Americans, or conversely, direct learning may cause students to seek out additional direct learning.

However, in both exchange and non-exchange groups, films were the most common means of learning about Americans (reported by about $22 \%$ overall), possibly due to their accessibility and a belief that they accurately represent American life. Opinion about American music, movies, and television also was related to opinion about Americans; those with one point $(25 \%)$ higher opinion this American media also had a $5 \%$ higher opinion score of Americans. Classes, both at the school and university levels, were largely not reported as a method of learning about Americans, though this may partially be due to the fact that only $13 \%$ of students reported taking classes on Americans.

In addition to opinion about American media, variables significantly associated with a positive opinion about Americans were opinion about American ideas about democracy, desire to travel to the U.S. and opinion about the U.S.

Our study reconfirmed the common finding in similar research that politics play a large role in opinion of the U.S.; survey comments supported this point by often mentioning U.S. intervention in Middle Eastern countries. Yet not all U.S. government aspects were disliked; the de juris idea of American democracy was seen in a very positive light, though its de facto application was viewed negatively. Mistranslation of cultures was also prevalent, as American customs and ideas seemed to be valued by respondents, but these aspects spreading in Jordan was viewed overall as negative due to the idea that they were incorrectly represented in a manner contrary to the culture. In a related vein, both groups used stereotypes in their responses, though these were more prevalent in non-participants and may have been explained by a low confidence in knowledge.

\section{Suggestions for Further Study}

As films are the most commonly reported method of learning about Americans, a deeper analysis of their effect on this learning is sug- gested. Our findings show that a higher opin ion of media relates to a higher opinion of Americans, so to better perception of Americans in the region, perhaps access to more representational movies would ease and facilitate better learning about American culture. Studies pursuing this potential are suggested.

A more expansive study of exchange participants is also recommended. A large enough sample size was not available during the time our study was conducted due to the limited number of students participating in exchange programs, so potentially meaningful associations may have gone undetected by our study. The higher average opinion on Americans, in addition to the higher caliber of survey responses of exchange participants, indicates to the potential for an important impact on students from these programs.

In addition, studies at different universities across Jordan are also suggested to expand the variety and number of respondents. Due to Gibson's former participation in one of the cross-cultural exchange programs, and Banihani's current position as a Yarmouk professor, it is understood that these associations may have unconsciously affected student respondents, though students were in no way required or pressured to participate in any capacity.

\section{References}

Arab American Institute. (2004). Impressions of America. Zogby Research Services. From http://www.aaiusa.org/index_ee.php/r eports/impressions-of-america-2004.

Arab American Institute. (2014). 5 Years After the Cairo Speech: How Arabs View President Obama and America. Zogby Research Services. From: http://www.aaiusa.org/reports/5-yearsafter-the-cairo-speech-how-arabs-viewpresident-obama-and-america/.

Bennett, M. J. (1993). Towards ethnorelativism: A developmental model of intercultural sensitivity. In R. M. Paige (Ed.), Education for the intercultural experience (pp. 21-71). Yarmouth, ME: Intercultural Press.

Elfenbein, H.A., \& Ambady, N. (2003, October). Universals and Cultural Differences in Recognizing Emotions. American Psychological Society 12(5), 159-64. 
Falomir- Pichastor, J., Manuel, J., MuñozRojas, D., Invernizzi, F., and Mugny, G. (2004).Perceived In-group Threat as a Factor Moderating the Influence of In-group Norms on Discrimination against Foreigners. European Journal of Social Psychology (34)2, pp. 135-53. Wiley Online Library.

Freeman, Jonathan B., Nicholas O. Rule, and Ambady, N. (2009). The Cultural Neuroscience of Person Perception. Progress in Brain Research 178 (2009): 191-201. Dartmouth University. From: Web. 22 June 2014: <http://www.dartmouth.edu/ freemanl ab/pubs/Freeman_PBR.pdf>.

Herrnstein, R. J, and Charles A. M. (1994). The Bell Curve: Intelligence and Class Structure in American Life. New York: Free Press.

http://www.interruptions.net/literature /Ulijn-TechComm00.pdf

Kitayama S., Duffy S, Kawamura T, and Larsen J. (2003 May). Perceiving an object and its context in different cultures: a cultural look at new look. Psychological Science, (14) 3. 201-06. USA: University of Southern California.

Kohut, Andrew (2005). Arab and Muslim Perceptions of the United States. Pew Research Center. Retreived on 24 June 2014 from: <http://www.pewresearch.org/2005/11 /10/arab-and-muslim-perceptions-ofthe-united-states $/>$.

PBS (2002). What Are Some Typical Misperceptions and Stereotypes Westerners Hold about Islam and the Middle East, and Vice Versa? Global Connections: the Middle East. From:

http://www.pbs.org/wgbh/globalconne ctions/mideast/questions/types/index.h tml? pagewanted=all.

Pew Research Center. (2002-2013a). American Ideas and Customs. Pew Research Centers Global Attitudes Project RSS. From: http://www.pewglobal.org/database/in dicator/42/survey/all/.

Pew Research Center. (2002-2013b). Opinion of Americans. Pew Research Centers Global Attitudes Project RSS. From: www.pewglobal.org/database/indicator /2/survey/all/

Pew Research Center. (2002-2013c). Opinion of the United States. Pew Research Centers Global Attitudes Project RSS. From: http://www.pewglobal.org/database/in dicator/1/survey/all/.

Said, Edward W. (2001, Oct. 4). The Clash of Ignorance. The Nation. USA.

Telhami, Shibley. (2010). 2010 Annual Arab Public Opinion Survey. Brookings. From: http:/ / www.brookings.edu/ /media/re search/files/reports/2010/8/05\%20arab \%20opinion \%20poll\%20telhami/0805_ara bic_opinion_poll_telhami.pdf.

Tessler, M., and Robbins, M. (2007). What Leads Some Ordinary Arab Men and Women Approve of Terrorist Acts against the United States? JSTOR. Journal of Conflict Resolution. From: <http://www.jstor.org/stable/27638550.

Ulijn, J. M. and Amant, K. (2000). Mutual Intercultural Perception: How Does It Affect Technical Communication? Some Data from China, the Netherlands, Germany, France, and Italy. Technical Communication. 